\title{
Gravidez na Adolescência
}

Marta Edna Holanda Diógenes Yazlle

A adolescência corresponde ao período da vida entre os 10 e 19 anos, no qual ocorrem profundas mudanças, caracterizadas principalmente por crescimento rápido, surgimento das características sexuais secundárias, conscientização da sexualidade, estruturação da personalidade, adaptação ambiental e integração social.

Com a introdução dos cuidados de puericultura, melhores condições nutricionais, programas de vacinação, entre outros, tem havido diminuição da mortalidade infantil, o que resulta no aumento da população de adolescentes. No Brasil, corresponde a $20,8 \%$ da população geral, sendo $10 \%$ na faixa de 10 a 14 anos e $10,8 \%$ de 15 a 19 anos, estimando-se que a população feminina seja de 17.491 .139 pessoas ${ }^{1}$.

A análise do perfil de morbidade desta faixa da população tem revelado a presença de doenças crônicas, transtornos psico-sociais, fármaco-dependência, doenças sexualmente transmissíveis e problemas relacionados à gravidez, parto e puerpério.

A gravidez neste grupo populacional vem sendo considerada, em alguns países, problema de saúde pública, uma vez que pode acarretar complicações obstétricas, com repercussões para a mãe e o recém-nascido, bem como problemas psico-sociais e econômicos.

Quanto à evolução da gestação, existem referências a maior incidência de anemia materna, doença hipertensiva específica da gravidez, desproporção céfalo-pélvica, infecção urinária, prematuridade, placenta prévia, baixo peso ao nascer, sofrimento fetal agudo intra-parto, complicações no parto (lesões no canal de parto e hemorragias) e puerpério (endometrite, infecções, deiscência de incisões, dificuldade para amamentar, entre outros) $)^{2-5}$.

No entanto, alguns autores sustentam a idéia de que, a gravidez pode ser bem tolerada pelas adolescentes, desde que elas recebam assistência pré-natal adequada, ou seja, precocemente e de forma regular, durante todo o periodo gestacional ${ }^{6}$, o que nem sempre acontece, devido a vários fatores, que vão desde a dificuldade de reconhecimento e aceitação da gestação pela jovem até a dificuldade para o agendamento da consulta inicial do pré-natal.

Têm sido citados também efeitos negativos na qualidade de vida das jovens que engravidam, com prejuízo no seu crescimento pessoal e profissional ${ }^{7,8}$. Segundo Blum ${ }^{9}, 53 \%$ das adolescentes que engravidam completam o segundo grau, enquanto que, entre as adolescentes que não engravidam, essa cifra corresponde a 95\%. Há, portanto, necessidade de avaliação quantitativa e qualitativa da questão, principalmente nos países em desenvolvimento, para verificação da necessidade da adoção de medidas pertinentes a sua prevenção e direcioná-las aos grupos mais vulneráveis.

Os países desenvolvidos estão, há algum tempo, interessados nesta questão. Nos Estados Unidos, Spitz et al. (1996) ${ }^{10}$, ocorreu um aumento de 8,8\% em 1980 para 9,6\% em 1990, na população de 15 a 19 anos e, de 7,4\% em 1980 para 8,4\% em 1990, na população com menos de 15 anos ${ }^{11}$. No Brasil tem sido referido aumento da incidência da gravidez nesta faixa etária, com cifras que vão de 14 a $22 \%{ }^{8,12-14}$. Alguns estudos têm sido realizados, sugerindo a necessidade de estratégias para a prevenção devido às repercussões negativas sobre a saúde do binômio mãe-filho e principalmente, sobre as perspectivas de vida futura de ambos.

As tentativas de prevenção devem levar em consideração o conhecimento dos chamados fatores predisponentes ou situações precursoras da gravidez na adolescência, tais como: baixa auto-estima, dificuldade escolar, abuso de álcool e drogas, comunicação familiar escassa, conflitos familiares, pai ausente e ou rejeitador, violência física, psicológica e sexual, rejeição familiar pela atividade sexual e gravidez fora do casamento. Tem sido ainda referidos: separação dos pais, amigas grávidas na adolescência, problemas de saúde e mães que engravidaram na adolescência ${ }^{15}$. Por outro lado, alguns estudos sugerem que, entre as adolescentes que não engravidam, os pais têm melhor nivel de educação, maior religiosidade e ambos trabalham fora de casa ${ }^{16,17}$.

É importante lembrar também, que deve ser incluída nas estratégias de prevenção, a averiguação de atitudes frente a adolescente que engravidou. Existem evidências do abandono escolar, por pressão

Professora Doutora do Departamento de Ginecologia e Obstetrícia da Faculdade de Medicina de Ribeirão Preto-USP e responsável pelo Setor de Anticoncepção do Departamento de Ginecologia e Obstetrícia da Faculdade de Medicina de Ribeirão Preto-USP.

Correspondência: Av. Bandeirantes, 3900 - Departamento de Ginecologia e Obstetricia - 14049-900 - Ribeirão Preto - SP - tel.: (16)3602-2587 - e-mail: mehyazll@fmrp.usp.br 
da família, pelo fato da adolescente sentir vergonha devido à gravidez, e ainda, por achar que "agora não é necessário estudar". Pode haver também rejeição da própria escola, por pressão dos colegas ou seus familiares e até de alguns professores. Em 1990, Upchurch e McCarthy ${ }^{18}$ relataram em seu estudo que, $39 \%$ de adolescentes grávidas abandonaram a escola, enquanto que entre as não grávidas o abandono foi de 19\%. Quanto ao retorno à escola e graduação, 30\% de adolescentes que tinham engravidado voltaram e concluíram os estudos; quando não houve gravidez essa cifra correspondeu a $85 \%$.

É importante, na abordagem de medidas preventivas, considerar quais adolescentes estão mais expostas ao risco de engravidar. Entre 7.134 partos de adolescentes ocorridos no município de Ribeirão Preto, São Paulo, observa-se entre gestantes adolescentes, cifras significantemente maiores entre aquelas atendidas pelo Sistema Único de Saúde (SUS), quando comparadas com jovens atendidas pelo sistema pré-pago (Convênio ou Particular), ou seja: 2,1\% corresponderam a categoria particular, 17,9\% a categoria convênio e 80,0\% a categoria SUS. Segundo Rocha et al. (1997) ${ }^{19}$ a categoria de internação pode representar a categoria social ao qual o indivíduo pertence, considerando o grupo atendido pelo SUS, como população de baixa renda.

Esses dados são preocupantes devido às possiveis repercussões psico-sociais acarretadas pela gestação precoce. Considerando-se que, a gravidez na adolescência pode resultar no abandono escolar e que, o retorno aos estudos se dá em menores proporções, torna-se difícil a profissionalização e o ingresso no grupo de população economicamente ativa, com agravamento das condições de vida de pessoas já em situação econômica desfavorável ${ }^{18,20,21}$.

Consideramos de grande importância conhecer a problemática no Brasil, em suas diferentes regiões, bem como identificar a população mais vulnerável aos efeitos negativos, que a gravidez possa acarretar, tanto para a mãe como para a criança. Assim devem ser estimulados os projetos e programas que visam a abordagem do tema, principalmente no que diz respeito a sua prevenção e também viabilizar publicações a esse respeito.

Neste sentido encontramos publicado no presente número deste valioso periódico, trabalho cujo capítulo é Gestação na Adolescência Precoce e Tardia - há diferença nos riscos obstétricos. Trata-se de estudo transversal, com avaliação analítica de um número considerável de adolescentes grávidas, atendidas em centro de atendimento terciário, considerando-se variáveis relacionadas a evolução da gestação e condições do recém-nascido, retratando de maneira adequada alguns aspectos da gestação na adolescência.

\section{Referências}

1. Instituto Brasileiro de Geografia e Estatística (IBGE). Censo demográfico, 2000. Rio de Janeiro; 2001.

2. Ribeiro ERO, Barbieri MA, Bettiol H, Silva AAM. Comparação entre duas coortes de mães adolescentes em município do sudeste do Brasil. Rev Saúde Pública. 2000;34(2):136-42.

3. Jolly MC, Sebire N, Harris J, Robinson S, Regan L. Obstetric risks of pregnancy in woman less than 18 years old. Obstet Gynecol. 2000;96(6):962-6.

4. Nogueira NM, Marreiro DN, Parente JV, Cozzolino SM. [Utilization of different iron concentrations on pregnant adolescents also supplemented with zinc and folate[. Arch Latinoam Nutr. 2001;51(3):225-9. Portuguese.

5. Costa MC, Santos CAT, Nascimento Sobrinho CL, Freitas JO, Ferreira KASL, Silva MA, et al. Childbirth and live newborns of adolescent and young adult mothers in the municipality of Feira de Santana, Bahia State, Brazil, 1998. Cad Saúde Pública. 2002;18(3):715-22.

6. Lao TT, Ho LF. The obstetric implications of teenage pregnancy. Hum Reprod. 1997;12(10):2303-5.

7. Fraser AM, Brockert JE, Ward RH. Association of young maternal age with adverse reproductive outcomes. N Engl J Med. 1995;332(17):1113-7.

8. Michelazzo D, Yazlle MEHD, Mendes MC, Patta MC, Rocha JSY, Moura MD. Indicadores sociais de grávidas adolescentes: estudo caso-controle. Rev Bras Ginecol Obstet. 2004;26(8):633-9.

9. Blum RW, Geer L, Hutton L, McKay C, Resnick MD, Rosenwinkel K, et al. The Minnesota Adolescent Health Survey. Implications for physicians. Minn Med. 1998;71(3):143-5, 149.

10.Spitz AM, Velebil P, Koonin LM, Strauss LT, Goodman KA, Wingo P, et al. Pregnancy, abortion, and birth rates among US adolescents - 1980, 1985, and 1990. JAMA. 1996;275(13):989-94. 
11.Lesser J, Escoto-Lloyd S. Health-related problems in vulnerable population: pregnant teens and adolescent mothers. Nurs Clin North Am. 1999;34(2):289-99.

12.Prado LV. Gravidez não planejada. Adolescência. 1996;45(1):23-4.

13. Yazlle MEHD, Mendes MC, Patta MC, Rocha JSY, Azevedo GD, Marcolin AC. A adolescente grávida: alguns indicadores sociais. Rev Bras Ginecol Obstet. 2002;24(9):609-14.

14. Ministério da Saúde. Secretaria de Assistência à Saúde (SAS). DATASUS. Sistema de Informações Hospitalares (SIH/SUS). Brasília; 2004.

15.Patta MC, Borsatto PL. Características do comportamento sexual de adolescentes grávidas. In: Gir E, Yazlle MEHD, Cassiani SHB, Caliri MHL, organizadores. Sexualidade em temas. Ribeirão Preto: FUNPEC; 2000. p. 37-53.

16. Rocha JSY, Simões BJG. Estudo da assistência hospitalar pública e privada em bases populacionais, 19861996. Rev Saúde Pública. 1999;33(1):44-54.

17. Guijarro S, Naranjo J, Padilla M, Gutierez R, Lammers C, Blum RW. Family risk factors associated with adolescent pregnancy: study of a group of adolescent girls and their families in Ecuador. J Adolesc Health. 1999;25(2):166-72.

18.Upchurch DM, McCarthy J. The timing of a first birth and high-school completion. Am Sociol Rev. 1990;55(2): 224-34.

19. Rocha JSY, Simões BJG, Guedes GLM. Assistência hospitalar como indicador da desigualdade social. Rev Saúde Pública. 1997;31(5):479-87.

20.Stevens-Simon C, Lowy R. Teenage childbearing. An adaptive strategy for the socioeconomically disadvantaged or a strategy for adapting to socioeconomic disadvantage? Arch Pediatr Adolesc Med. 1995;149(8):912-5.

21.Phipps MG, Sowers M. Defining early adolescent childbearing. Am J Public Health. 2003;92(1):125-8. 